\title{
Optimal timing for precutting in cases with difficult biliary cannulation
}

\section{다)(요 $\odot$}

\author{
Authors \\ Yuichi Takano, Masatsugu Nagahama, Fumitaka Niiya, Takahiro Kobayashi, Eiichi Yamamura, Naotaka Maruoka
}

Institution

Division of Gastroenterology, Department of Internal

Medicine, Showa University Fujigaoka Hospital, Yokohama,

Kanagawa, Japan

submitted 6.1.2018

accepted after revision 20.2.2018

Bibliography

DOI https://doi.org/10.1055/a-0599-6260 |

Endoscopy International Open 2018; 06: E1015-E1019

(c) Georg Thieme Verlag KG Stuttgart · New York

ISSN 2364-3722

Corresponding author

Yuichi Takano, 1-30 Fujigaoka, Aoba-ku, Yokohama-shi,

Kanagawa 227-8501, Japan

Fax: +81-45-9731019

yuichitakano1028@yahoo.co.jp

\section{ABSTRACT}

Background and study aims In endoscopic retrograde cholangiopancreatography (ERCP), precutting is widely used when achieving biliary cannulation is difficult. However, no consensus has been reached with regard to the best time to initiate precutting.
Patients and methods We retrospectively examined 63 patients who underwent precutting for naïve papilla with difficulty in biliary cannulation between 2009 and 2016. The outcomes of the early precut group ( $\leq 20$ min from cannulation until initiating precutting) and the late precut group (> 20 min) were compared.

Results Of the 63 patients, 17 (27\%) were in the early precut group and 46 (73\%) were in the late precut group; median time until the initiating precutting was 28 minutes $(7-50)$. No significant difference was observed between the two groups in terms of clinical features (age, sex, and indication for ERCP), precutting method, and rate of pancreatic duct stent placement. Significantly higher rates of successful biliary cannulation were observed in the early precut group $(16 / 17 ; 94 \%)$ than in the late precut group (32/46; 70\%) $(P<0.05)$. In 13 patients in whom precutting was commenced after 40 minutes, the rate of successful biliary cannulation was very low at $53 \%$ (7/13). No significant difference was found between the two groups in terms of incidence of complications (pancreatitis in 5 patients and bleeding in 1 patient).

Conclusion In actual clinical practice, precutting is commenced approximately 30 minutes after cannulation; however, to successfully achieve biliary cannulation, precutting is recommended to be performed within 20 minutes. Precutting is effective when little inflammation and swelling of the ampulla of Vater is observed. This study was limited in that it was single-center, retrospective and had a small subject sample.

\section{Introduction}

Endoscopic retrograde cholangiopancreatography (ERCP) is essential for treating pancreaticobiliary diseases, and biliary and pancreatic duct deep cannulation is the most fundamental technique involved in ERCP. In ERCP, performing biliary cannulation is difficult in $5 \%$ to $18 \%$ of patients $[1,2]$. Therefore, various techniques such as wire-guided cannulation (WGC) [3-5], pancreatic guidewire-assisted cannulation [6], double guidewire technique [7,8], precutting [9], and endoscopic ultrasound-guided rendezvous technique [10] have been developed to improve the rate of successful cannulation. Precutting is cur- rently an established technique that is widely performed for biliary cannulation. However, the optimal time to initiate precutting remains controversial [11].

Several trials have recently compared an early precut group against a late precut group for cases with difficult biliary cannulation [12-17]. Meta-analyses [18-21] revealed no difference between the two groups with regard to the rate of successful biliary cannulation; however, the rate of pancreatitis could be low in the early precut group, i. e., early precutting effectively helped in preventing pancreatitis but did not help in improving the rate of biliary cannulation. However, these studies were prospective trials that were conducted at high-volume centers, 
where even in the late precut group, precutting was performed relatively early at 12 to 20 minutes after cannulation. In routine clinical practice, some cases often require, for various reasons, $\geq 20$ minutes before precutting is initiated. This study retrospectively assessed precutting for cases with difficult biliary cannulation to determine the optimal time to initiate precutting.

\section{Patients and methods}

Among 3,260 patients who underwent ERCP at our hospital between 2009 and 2016, 72 were excluded for surgically altered anatomy, 116 were excluded for the purpose of pancreatography, and 1621 were excluded for post-EST (endoscopic sphincterotomy) or EPBD (endoscopic papillary balloon dilation) papilla. Of 1451 patients with naïve papilla and for biliary cannulation, 63 who underwent precutting for difficult biliary cannulation were retrospectively examined. The patients were divided into the early precut group ( $\leq 20 \mathrm{~min}$ from cannulation until initiating precutting) and the late precut group (>20 min), and the outcomes of each group were compared ( $\mathbf{F i g} \mathbf{1} \mathbf{1})$.

Examination items included clinical features (e.g., age, sex, and indication for ERCP), precutting method, rate of pancreatic duct stent placement, rate of successful biliary cannulation, and complications. For complications, the classification of Cotton et al. [9] was used.

The first choice of cannulation method was using a catheter cannula with a contrast medium, and if that was impossible, WGC was performed. If a guidewire was inserted into the pancreatic duct, pancreatic guidewire cannulation was performed 5 to 10 times. However, when this technique proved unsuccessful, double guidewire technique was performed 5 to 10 times in all cases. When pancreatic intubation proved impracticable, cannulation was attempted 10 to 20 times prior to precutting.

For precutting, transpancreatic biliary sphincterotomy (TPBS) is performed using a pull-type sphincterotome when the guidewire can be inserted into the pancreatic duct. When the guidewire cannot be inserted into the pancreatic duct, the conventional precut technique (cutting from the orifice of the ampulla of Vater toward the bile duct using a needle knife) is performed.

At our hospital, before being allowed to precut, endoscopists should have performed at least 100 endoscopic sphincterotomies with a biliary cannulation rate for naïve papilla of at least $80 \%$. The timing of precutting and pancreatic duct stent placement is determined at the discretion of the endoscopist.

Statistical analyses were performed using the student's $t$ test and chi-square test to compare the two groups, and probability $(P)$ values $<0.05$ were considered to indicate a statistically significant difference.

\section{Results}

Mean age of the patients was 73.6 (32-95) years, and the male-to-female ratio was 34:29. The indication for ERCP was choledocholithiasis in 30 patients, malignant biliary stricture in 28 (pancreatic cancer in 19 and bile duct carcinoma in
Total 3260 ERCP between 2009 and 2016

- 72 were excluded for surgically altered anatomy

- 116 were excluded for the purpose of pancreatography

- 1621 were excluded for post-EST* or EPBD**

1451 ERCP with naive papilla and for biliary cannulation $\downarrow$

63 underwent precutting for difficult biliary cannulation

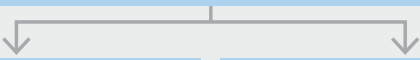

Early precut group

$(\leq 20 \mathrm{~min}) \mathrm{n}=17$

Late precut group

$(>20$ min) $n=46$

*EST: Endoscopic sphincterotomy

**EPBD: Endoscopic papillary balloon dilation

- Fig. 1 Algorithm for case selection.

nine), benign biliary stricture in four (chronic pancreatitis), and bile leakage in one. The precutting method employed was TPBS in 52 patients and the conventional precut technique in 11 patients ( $\triangleright$ Fig. $\mathbf{2}$, $>$ Fig. $\mathbf{3}$ ).

There were $17(27 \%)$ patients in the early precut group and $46(73 \%)$ in the late precut group; median time from cannulation until initiating precutting was 28 minutes (range 7-50). Pancreatic duct stents were placed in 39 patients (62\%).

A comparison of the outcomes of the early and late precut groups is presented in $\downarrow$ Table 1 . For both groups, clinical features (age, sex, and indication for ERCP), precutting method, and rate of pancreatic duct stent placement were comparable. Significantly higher rates of successful biliary cannulation were observed in the early precut group $(16 / 17 ; 94 \%)$ than in the late precut group $(32 / 46 ; 70 \%)(P<0.05)$. In 13 patients in whom precutting was initiated after 40 minutes, the rate of successful biliary cannulation was very low at $53 \%$ (7/13).

Complications included pancreatitis (5 patients) and bleeding ( 1 patient). Among patients with pancreatitis, the condition was moderate according to Cotton's classification in one patient and mild in all other patients. The incidence of post-ERCP pancreatitis (PEP) was $1 / 17$ (5.9\%) in the early precut group and $4 / 46(8.7 \%)$ in the late precut group. No significant difference was observed between the two groups in terms of complications.

\section{Discussion}

Precutting is an established technique that is widely performed in ERCP for cases with difficult biliary cannulation. However, the optimal time to initiate precutting remains controversial.

Several studies have recently compared outcomes in the early precut group with those in the late precut group (precutting performed after continuing normal cannulation) for cases with difficult biliary cannulation cases [12-17]. Meta-analyses re- 

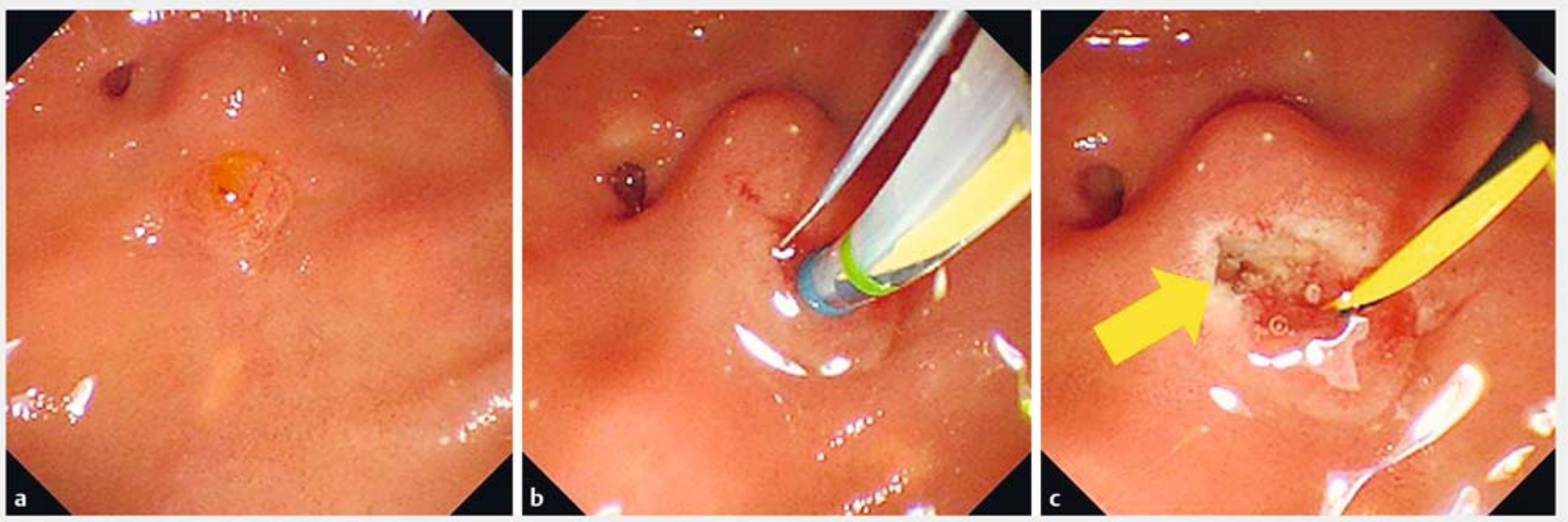

- Fig. 2 a Ampulla of Vater before cannulation. b The ampulla at 9 minutes after cannulation. The guidewire is inserted into the pancreatic duct. Negligible swelling and inflammation are observed in the ampulla of Vater. c The ampulla after transpancreatic biliary sphincterotomy. Biliary cannulation was successful. The arrow indicates the bile duct orifice.
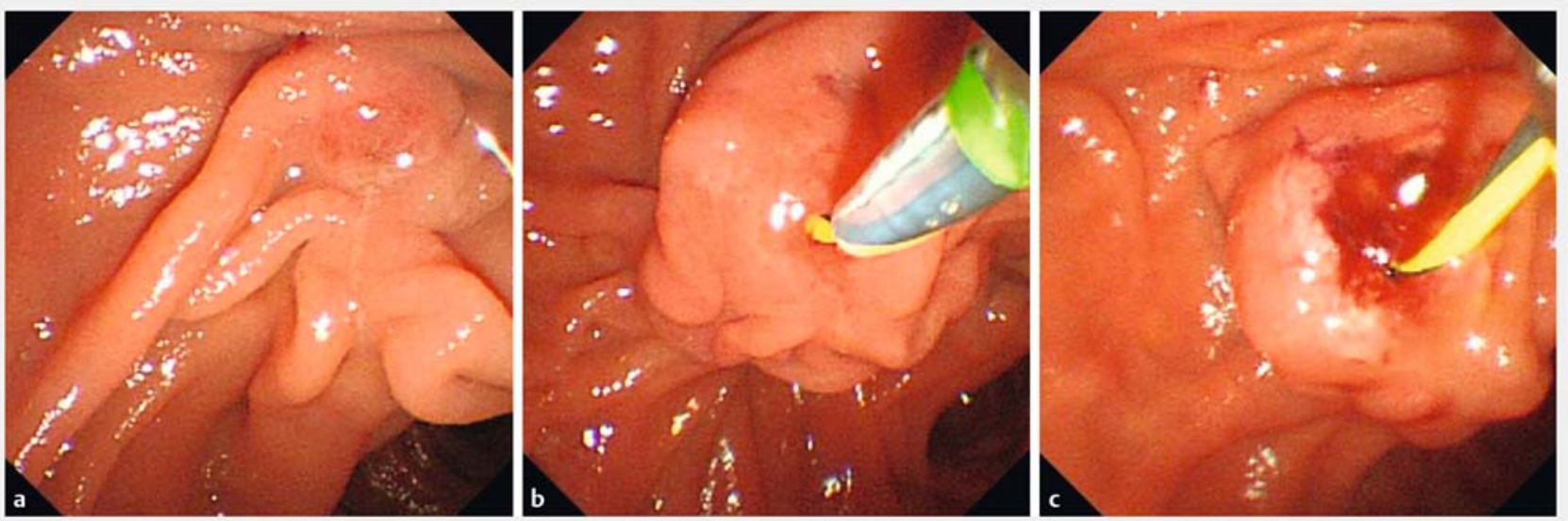

- Fig. 3 a The ampulla of Vater before cannulation. b The ampulla at 43 minutes after cannulation. Swelling of the papilla is observed as a result of cannulation for a long period. The guidewire is inserted into the pancreatic duct. c The ampulla of Vater after transpancreatic biliary sphincterotomy. Even after precutting, biliary cannulation was unsuccessful.

- Table 1 Comparison of early and late precut groups.

\begin{tabular}{|c|c|c|c|}
\hline & Early precut group $(n=17)$ & Late precut group $(n=46)$ & $P$ value \\
\hline Age, median (range) & $78(59-90)$ & $76(32-95)$ & n.s ${ }^{1}$ \\
\hline Sex (male:female) & 10,7 & 24,22 & $\mathrm{n} . \mathrm{s}^{2}$ \\
\hline Indication for ERCP & Benign disease 9 , malignant disease 8 & Benign disease 26 , malignant disease 20 & n.s. ${ }^{2}$ \\
\hline Precutting method & TPBS 14, CP 3 & TPBS 38, CP 8 & n.s. ${ }^{2}$ \\
\hline Pancreatic stent placement & $9 / 17(53 \%)$ & $30 / 46(65 \%)$ & $\mathrm{n} . \mathrm{s}^{2}$ \\
\hline Success of biliary cannulation & $16 / 17(94 \%)$ & $32 / 46(70 \%)$ & $<0.05^{2}$ \\
\hline Complication & 2 (one pancreatitis and one bleeding) & 4 (pancreatitis) & n.s. ${ }^{2}$ \\
\hline
\end{tabular}


vealed no difference between the two groups in terms of the rate of successful biliary cannulation, and risk for pancreatitis could be lowered by early precutting [18-21]. In other words, early precutting helped in preventing pancreatitis but did not help in improving the rate of biliary cannulation. However, due care should be paid to the fact that these studies were prospective trials conducted at high-volume centers, where even in the late precut group, precutting was performed relatively early at 12 to 20 minutes after cannulation.

In this study, the rate of successful biliary cannulation was significantly higher in the early precut group ( $\leq 20 \mathrm{~min}$ ) than the late precut group (>20 min) ( $94 \%$ vs. $70 \%$ ). Among patients in whom precutting was initiated after 40 minutes, the rate of successful biliary cannulation was poor, accounting for approximately half of the patients (53\%). Thus, cannulation is difficult in the event of swelling and inflammation of the ampulla of Vater, which result from a long period of continued cannulation. Precutting is useful when the papilla has little damage, and precutting should be performed within 20 minutes.

However, in this study, the median time before initiating precutting was 28 minutes, and precutting was initiated within 20 minutes in only 17 patients (26\%). This finding is believed to reflect actual clinical practice. The reasons for which time is required before precutting are that several cannulation techniques were performed before precutting and there is some resistance toward simply precutting.

Precutting requires a high level of skill, and only experts are permitted to perform the procedure $[22,23]$. Reported risks for precutting include pancreatitis, bleeding, and perforation, and precutting is reportedly an independent risk factor for pancreatitis [24]. Some endoscopists hope to avoid precutting if possible and hesitate to precut early.

Incidence of PEP was $1 / 17$ (5.9\%) in the early precut group and $4 / 46(8.7 \%)$ in the late precut group. Although the difference was not statistically significant, the late precut group exhibited a higher incidence of pancreatitis. A significant difference was possibly not found because the study included a small subject sample. As mentioned above, in meta-analyses, early precutting is suggested to be useful to prevent pancreatitis [18-21]. Pancreatitis recently has been considered to be caused by attempting cannulation for a long period, which damages the ampulla of Vater, rather than by precutting itself [18]. Performing early precutting is recommended to prevent pancreatitis.

In recent years, precut fistulotomy (incision of the mucosa starting directly over the roof of the papilla followed by upward or downward cut until the underlying biliary sphincter is visualized) has been the preferred modality for precutting using needle-knife, because incidence of PEP has been reported to be lower in patients who undergo fistulotomy than those who undergo conventional precutting $[22,23]$. Use of conventional precutting in the current study might have contributed to the relatively high incidence of PEP.

In the current study, a duration of 20 minutes was set as an index for precutting. However, many factors other than duration may dictate timing of precutting, such as frequency of attempted cannulation and guidewire insertion or injection of contrast agent into the pancreatic duct. Future research needs to further explore the correlation between these factors and the timing for precutting initiation.

\section{Conclusion}

In actual clinical practice, precutting is performed approximately 30 minutes after initiating cannulation. However, the rate of successful biliary cannulation is significantly higher when precutting is performed within 20 minutes than when it is performed after 20 minutes. For successful biliary cannulation, performing precutting is useful when the ampulla of Vater has little damage, and precutting should be performed within 20 minutes after initiating cannulation. This study was limited in that it was single-center, retrospective and had a small number of subjects in the sample. Because the experiment was not randomized, patient selection might have been biased.

\section{Competing interests}

None

References

[1] Testoni PA, Testoni S, Giussani A. Difficult biliary cannulation during ERCP: how to facilitate biliary access and minimize the risk of postERCP pancreatitis. Dig Liver Dis 2011; 43: 596 - 603

[2] Williams E], Taylor S, Fairclough P et al. BSG Audit of ERCP. Are we meeting the standards set for endoscopy? Results of a large-scale prospective survey of endoscopic retrograde cholangio-pancreatograph practice. Gut 2007; 56: 821 - 829

[3] Lella F, Bagnolo F, Colombo E et al. A simple way of avoiding postERCP pancreatitis. Gastrointest Endosc 2004; 59: 830-834

[4] Cennamo V, Fuccio L, Zagari RM et al. Can a wire-guided cannulation technique increase bile duct cannulation rate and prevent post-ERCP pancreatitis? A meta-analysis of randomized controlled trials. Am J Gastroenterol 2009; 104: 2343-2350

[5] Tse F, Yuan Y, Moayyedi P et al. Guide wire-assisted cannulation for the prevention of post-ERCP pancreatitis: a systematic review and meta-analysis. Endoscopy 2013; 45: 605-618

[6] Dumonceau JM, Devière J, Cremer M. A new method of achieving deep cannulation of the common bile duct during endoscopic retrograde cholangiopancreatography. Endoscopy 1998; 30: S80

[7] Herreros de Tejada A, Calleja JL et al. UDOGUIA-04 Group. Doubleguidewire technique for difficult bile duct cannulation: a multicenter randomized, controlled trial. Gastrointest Endosc 2009; 70: 700 - 709

[8] Ito K, Horaguchi J, Fujita $\mathrm{N}$ et al. Clinical usefulness of double-guidewire technique for difficult biliary cannulation in endoscopic retrograde cholangiopancreatography. Dig Endosc 2014; 26: $442-449$

[9] Cotton PB, Lehman G, Vennes J et al. Endoscopic sphincterotomy complications and their management: an attempt at consensus. Gastrointest Endosc 1991; 37: 383-393

[10] Mallery S, Matlock J, Freeman ML. EUS-guided rendezvous drainage of obstructed biliary and pancreatic ducts: Report of 6 cases. Gastrointest Endosc 2004; 59: $100-107$

[11] Testoni PA, Mariani A, Aabakken L et al. Papillary cannulation and sphincterotomy techniques at ERCP: European Society of Gastroin- 
testinal Endoscopy (ESGE) Clinical Guideline. Endoscopy 2016; 48: $657-683$

[12] Tang SJ, Haber GB, Kortan P et al. Precut papillotomy versus persistence in difficult biliary cannulation: a prospective randomized trial. Endoscopy 2005; 37: 58-65

[13] Cennamo V, Fuccio L, Repici A et al. xTiming of precut procedure does not influence success rate and complications of ERCP procedure: a prospective randomized comparative study. Gastrointest Endosc 2009; 69: $473-479$

[14] de Weerth A, Seitz U, Zhong Y et al. Primary precutting versus conventional over-the-wire sphincterotomy for bile duct access: a prospective randomized study. Endoscopy 2006; 38: 1235-1240

[15] Khatibian M, Sotoudehmanesh R, Ali-Asgari A et al. Needle-knife fistulotomy versus standard method for cannulation of common bile duct: a randomized controlled trial. Arch Iran Med 2008; 11: 16-20

[16] Zhou PH, Yao LQ, Xu MD et al. Application of needle-knife in difficult biliary cannulation for endoscopic retrograde cholangiopancreatography. Hepatobiliary Pancreat Dis Int 2006; 5: 590-594

[17] Manes G, Di Giorgio P, Repici A et al. An analysis of the factors associated with the development of complications in patients undergoing precut sphincterotomy: a prospective, controlled, randomized, multicenter study. Am J Gastroenterol 2009; 104: 2412 - 2417

[18] Cennamo V, Fuccio L, Zagari RM et al. Can early precut implementation reduce endoscopic retrograde cholangiopancreatography-relat- ed complication risk? Meta-analysis of randomized controlled trials. Endoscopy 2010; 42: $381-388$

[19] Gong B, Hao L, Bie L et al. Does precut technique improve selective bile duct cannulation or increase post-ERCP pancreatitis rate? A metaanalysis of randomized controlled trials. Surg Endosc 2010; 24: $2670-2680$

[20] Navaneethan U, Konjeti R, Venkatesh PG et al. Early precut sphincterotomy and the risk of endoscopic retrograde cholangiopancreatography related complications: An updated meta-analysis. World J Gastrointest Endosc 2014; 6: $200-208$

[21] Choudhary A, Winn J, Siddique $S$ et al. Effect of precut sphincterotomy on post-endoscopic retrograde cholangio-pancreatography pancreatitis: A systematic review and meta-analysis. World J Gastroenterol 2014; 20: $4093-4101$

[22] Mavrogiannis C, Liatsos C, Romanos A et al. Needle-knife fistulotomy versus needle-knife papillotomy for the treatment of common bile duct stones. Gastrointest Endosc 1999; 50: 334-339

[23] Katsinelos P, Gkagkalis S, Chatzimavroudis G et al. Comparison of three types of precut technique to achieve common bile duct cannulation: a retrospective analysis of 274 cases. Dig Dis Sci 2012; 57 : $3286-3292$

[24] Freeman ML, DiSario JA, Nelson DB et al. Risk factors for post-ERCP pancreatitis: a prospective, multicenter study. Gastrointest Endosc 2001; 54: $425-434$ 